\title{
ANALISIS STRATEGI BISNIS PADA PT. ERA GLOBAL PRIORITAS DI BANDAR LAMPUNG
}

\author{
Rahmat Tullah \\ Universitas Lampung \\ Rahmatttullah1997@gmail.com
}

\begin{abstract}
Abstrak. Penelitian ini bertujuan untuk mengetahui strategi bisnis yang digunakan oleh PT. Era Global Prioritas dan merekomendasikan prioritas strategi yang dianalisis dengan metode deskriptif dan tahapan formulasi-formulasi yaitu matriks IFE dan EFE, matriks IE, SWOT dan pemilihan alternatif strategi prioritas dengan menggunakan metode QSPM. Hasil penelitian berdasarkan matriks IFE dan EFE diperoleh total nilai sebesar 3.62 dan 3.05. Hasil perumusan dan pemetaan matriks IE PT. Era Global Priorits berada pada posisi Growth and Build (tumbuh dan bangun). Berdasarkan posisi perusahaan tersebut alternatif strategi yang tepat untuk digunakan oleh perusahaan adalah strategi insentif (penetrasi pasar, pengembangan pasar dan pengembangan produk). Hasil analisis SWOT dihasilkan 8 stategi yang kemudian diprioritaskan dengan metode QSPM yaitu Memperluas pangsa pasar melakukan promosi yang efektif dan efisien dengan jumlah nilai daya tarik (STAS) tertinggi sebesar 3.22. rekomendasi untuk PT. Era Global Prioritas sebaiknya terus melakukan perluasan jalinan kerjasama dengan berbagai pihak, manajemen mutu produk, meningkatkan efektifitas promosi, melakukan evaluasi pemasaran, meningkatkan promosi baik melalui internet baik media sosial maupun website, melakukan inovasi pemasaran, dan melakukan inovasi produk.
\end{abstract}

Kata kunci: Matriks IFE dan Matriks EFE, Matriks IE, Strategi Bisnis, Analisis SWOT, QSPM

\section{BUSINESS STRATEGY ANALYSIS IN PT. ERA GLOBAL PRIORITAS IN BANDAR LAMPUNG}

\author{
Rahmat Tullah \\ Universitas Lampung \\ Rahmatttullah1997@gmail.com
}

\begin{abstract}
This study aims to determine the business strategies used by PT. Era Global Prioritas and recommend priority strategies that are analyzed by descriptive methods and stages of formulations namely IFE and EFE matrix, IE matrix, SWOT and selection of priority strategy alternatives using the QSPM method. The results of the study based on the IFE and EFE matrices obtained a total value of 3.62 and 3.05 . The results of the IE Era Global Priorits formulation and mapping matrix are in Growth and Build positions (growing and building). Based on the position of the company the right alternative strategy to be used by the company is an incentive strategy (market penetration, market development and product development). The results of the SWOT analysis produced 8 strategies which were then prioritized with the QSPM method, namely expanding market share to conduct effective and efficient promotions with the highest number of attraction values (STAS) of 3.22. Recommendations for PT. Era Global Prioritas should continue to expand the collaboration with various parties, product quality management, increase promotion effectiveness, conduct marketing evaluations, improve promotion through the internet both social media and websites, make marketing innovations, make product innovations.
\end{abstract}

Keywords: IFE Matrix and EFE Matrix, IE Matrix, Business Strategy, SWOT Analysis, QSPM 


\section{PENDAHULUAN}

Perusahaan properti merupakan perusahaan yang bergerak dalam bidang pembangunan apartemen, perumahan, perkantoran, real estate dan sebagainya. Sektor properti Indonesia telah bangkit kembali setelah sekian lama mengalami keterpurukkan akibat krisis pada tahun 1997 (Hamidah et al., 2015). Bisnis properti di Indonesia merupakan salah satu bisnis yang mengalami perkembangan secara signifikan (Primananda et al., 2020) karena kebutuhan tempat tinggal merupakan kebutuhan dasar bagi setiap manusia (Isnaini \& Adnan, 2018) dan setiap manusia akan berusaha untuk dapat memenuhinya. Hal ini menyebabkan semakin banyaknya pembangunan rumah atau tempat tinggal (Tanrifaisal et al., 2020).

Perusahaan di bidang properti khususnya perumahan dan perkantoran, harus menempatkan orientasi kepada kepuasan konsumen sebagai tujuan utama (Prasastono \& Pradapa, 2012). Selain itu komponen penunjang kepemilikan rumah juga semakin mudah serta menjangkau beragam lapisan masyarakat, contohnya dengan kucuran KPR (kredit kepemilikan rumah) yang melimpah (Lesmana, 2020).

Saat ini perkembangan dunia bisnis meningkat dengan pesat dan mengalami persaingan yang sangat ketat (Septianita et al., 2014) khususnya di Indonesia, sehingga mendorong para pengusaha khusus di bidang properti untuk mampu menciptakan pemikiran-pemikiran baru, gagasangagasan baru, dan menawarkan produk inovatif (Rifa'i et al., 2019) agar dapat memberikan nilai lebih kepada konsumen. Hal-hal tersebut mengharuskan perusahaan untuk mengelola kegiatan bisnisnya dengan baik.

Setiap perusahaan yang melakukan kegiatan bisnis tersebut harus memiliki strategi bisnis yang tepat supaya tetap mendapatkan kepercayaan dari para konsumen serta dapat bersaing dengan para pesaing lainnya (Lakutomo, 2014). Strategi yang diterapkan perusahaan harus tepat, karena hal tersebut merupakan salah satu penentu kelangsungan hidup dipasar. Kecermatan para pebisnis dalam menyesuaikan produk atau jasa sesuai dengan kebutuhan masyarakat menjadi salah satu faktor penentu keberhasilan suatu bisnis dalam bertahan. Dengan demikian, hanya perusahaan berkualitaslah yang dapat bersaing, dan menguasai pasar (Sufriadi, 2018).

PT. Era Global Prioritas merupakan pengembang sekaligus pemasaran perumahan yang berdiri pada tanggal 05 Januari 2018, yang beralamat kantor di Jl. Nangka Perumahan Angkasa Estate Blok C No. 01 Kel. Sepang Jaya, Kec. Kedaton, Bandar Lampung. Adapun bank yang bekerjasama dengan PT. Era Global Prioritas yakni Bank BTN. Sebelumnya PT. Era Global Prioritas bernamakan PT. Tunas Indo Kreatif yang berdiri sejak 20 Oktober 2013 dan telah menyelesaikan pembangunan perumahan dan kios di 5 tempat yang hingga saat ini semua perumahan dan kios sudah terjual semua, 5 tempat tersebut yakni :

Tabel 1

Perumahan Yang Sudah Dibangun Oleh PT. Tunas Indo Kreatif

\begin{tabular}{cccc}
\hline No. & \multicolumn{1}{c}{ Perumahan } & Tipe & Jumlah Unit \\
\hline 1. & $\begin{array}{l}\text { Perumahan Green } \\
\text { Hill Estate } \\
\text { Perumahan Green } \\
\text { 2ukabumi }\end{array}$ & 47 Rumah \\
2. 8 Kios \\
Residence \\
3. & $\begin{array}{l}\text { Perumahan } \\
\text { Sumber Agung } \\
\text { Perumahan } \\
\text { Cempaka }\end{array}$ & $36 / 84$ & 3 Rumah \\
4. $36 / 72$ & 13 Rumah \\
Residence & $\begin{array}{l}\text { Perumahan Griya } \\
\text { Saka }\end{array}$ & $36 / 72$ & 54 Rumah \\
\hline
\end{tabular}

Sumber: PT. Tunas Indo Kreatif, 2017 
Sejak berganti nama menjadi PT. Era Global Prioritas, perusahaan sedang menjalankan pembangunan perumahan hingga saat ini di 2 tempat yakni Perumahan Era Prioritas tipe 36/72 dengan jumlah 105 unit dan Perumahan Era Global tipe 36/72 dengan jumlah 65 unit.

PT. Era Global Prioritas telah tergabung dalam Himpunan Pengembang Pemukiman dan Perumahan Rakyat (HIMPERRA) dan telah tergabung dalam Pusat Pengelolaan Dana Pembiayaan Perumahan (PPDPP) yang dinaungi oleh Kementerian Perumahan.

Tabel 2

Daftar Anggota yang Tergabung Dalam HIMPERRA Provinsi Lampung

\begin{tabular}{clc}
\hline No. & Nama Perusahaan & \multicolumn{1}{c}{ AHI } \\
\hline 1. & $\begin{array}{l}\text { PT. Waringin } \\
\text { Jaya Perdana }\end{array}$ & 18.18 .0001 \\
2. & $\begin{array}{l}\text { PT. Bumi Berkah } \\
\text { Madani }\end{array}$ & 18.18 .0002 \\
3. & $\begin{array}{l}\text { PT. Fajrina Citra } \\
\text { Persada }\end{array}$ & 18.18 .0003 \\
4. & $\begin{array}{l}\text { PT. Era Global } \\
\text { Prioritas }\end{array}$ & 18.18 .0004 \\
5. & $\begin{array}{l}\text { PT. Lampung } \\
\text { Maju Bersama }\end{array}$ & 18.18 .0005 \\
6. & $\begin{array}{l}\text { PT. Purnama } \\
\text { Damai Mandiri }\end{array}$ & 18.18 .0006 \\
\hline
\end{tabular}

Sumber: Himpunan Pengembang Pemukiman dan Perumahan Rakyat (HIMPERRA) Lampung, 2018

Tabel di atas merupakan daftar perusahaan properti yang tergabung dalam Himpunan Pengembang Pemukiman dan Perumahan Rakyat (HIMPERRA) Lampung. Banyaknya pesaing maka perusahaan berlomba-lomba dalam memenangkan persaingan bisnis dengan memberikan kualitas dan harga yang terjangkau oleh konsumennya.

Tabel 3

Jumlah Unit Rumah yang Terelisasi oleh Perusahaan yang Tergabung dalam HIMPERRA Tahun 2018

\begin{tabular}{|c|c|c|}
\hline No. & Nama Perusahaan & Jumlah Unit Rumah \\
\hline 1. & $\begin{array}{l}\text { PT. Waringin } \\
\text { Jaya Perdana }\end{array}$ & 33 \\
\hline 2. & PT. Bumi Berkah & 98 \\
\hline
\end{tabular}

\begin{tabular}{|c|c|c|}
\hline & Madani & \\
\hline 3. & $\begin{array}{l}\text { PT. Fajrina Citra } \\
\text { Persada }\end{array}$ & 148 \\
\hline 4. & $\begin{array}{l}\text { PT. Era Global } \\
\text { Prioritas }\end{array}$ & 170 \\
\hline 5. & $\begin{array}{l}\text { PT. Lampung } \\
\text { Maju Bersama }\end{array}$ & 130 \\
\hline 6. & $\begin{array}{l}\text { PT. Purnama } \\
\text { Damai Mandiri }\end{array}$ & 60 \\
\hline & TOTAL & 943 \\
\hline
\end{tabular}

Sumber: Himpunan Pengembang Pemukiman dan Perumahan Rakyat (HIMPERRA) Lampung, 2018

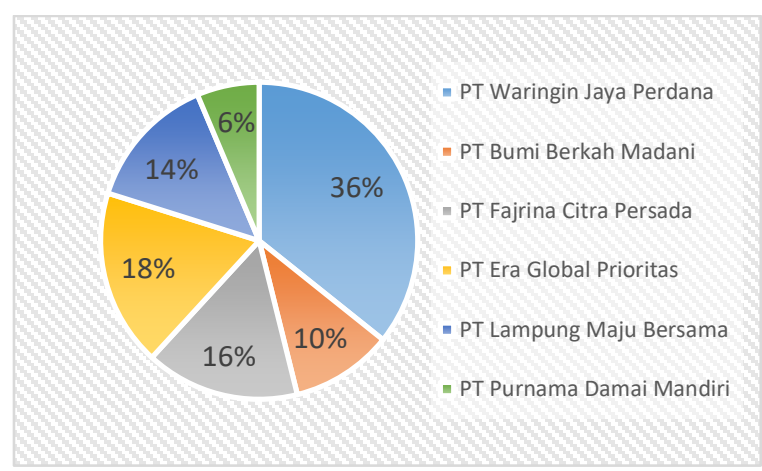

Gambar 1. Persentase Jumlah Unit Rumah yang Terelisasi oleh Perusahaan yang Tergabung dalam HIMPERRA Tahun 2018

Tabel 3 dan gambar 1 di atas adalah jumlah unit rumah yang terealisasi oleh perusahaan yang tergabung dalam Himpunan Pengembang Pemukiman dan Perumahan Rakyat (HIMPERRA) Lampung. Berdasarkan tabel dan gambar di atas, posisi perusahaan berada di urutan ke 2 dari 6 perusahaan, dimana pesaing utama PT. Era Global Prioritas yang berada di atasnya yaitu PT. Waringin Jaya Perdana dan tepat dibawahnya adalah adalah PT. Fajrina Citra Persada.

Keunggulan dari PT. Era Global Prioritas adalah memiliki kantor pelayanan konsumen yang dekat dengan perumahanperumahan sehingga lokasinya mudah dijangkau oleh konsumennya. Kantor pelayanan konsumen melayani 7 hari dalam seminggu yaitu buka pada hari senin sampai minggu, pada hari libur yaitu minggu, banyak konsumen yang ingin mendatangi kantor pelayanan dan survei atau cek lokasi. 
Dalam menarik minat konsumen PT. Era Global Prioritas menawarkan DP atau uang muka yang dapat dijangkau oleh masyarakat menengah ke bawah, konsumen juga mendapatkan Sertfikat Hak Milik (SHM) serta PT. Era Global Prioritas telah bekerjasama dengan BTN Properti dalam program pemerintah yaitu rumah subsidi yang pada hal ini juga membuat keterjaminan modal perusahaan saat membangun.

PT. Era Global Prioritas dalam menghasilkan produk selalu berusaha menghasilkan produk yang berkualitas sehingga produknya dapat diterima oleh masyarakat dan konsumennya puas. Dalam menghasilkan produk yang berkualitas, PT. Era Global Prioritas menggunakan bahan baku bangunan yang bermutu atau berkualitas dan selalu mengontrol setiap pembangunan yang digarap oleh kontraktor dengan membentuk tim pengawas strandar mutu bangunan. Pengetahuan konsumen atau citra perusahaan dimata konsumen amat baik, keadaan teknologi yang semakin berkembang menjadi peluang dari PT. Era Global Prioritas untuk memanfaatkannya dan dukungan dari pemerintah terkait adanya program rumah subsidi.

Bahan baku bangunan yang digunakan PT. Era Global Prioritas juga berkualitas dan sesuai standarnya, hal itu dibuktikan dengan penggunaan material atau bahan baku bangunan seperti penggunaan besi pada rumah tipe 36/72 menggunakan besi ukuran $10 \mathrm{ks}$ dan penggunakan material lainnya seperti semen menggunakan Semen Padang dan takaran perbandingan antara jumlah semen dan pasir yang semua pengerjaan tersebut diawasi oleh tim pengawas standar mutu bangunan.

\begin{tabular}{|c|c|c|c|c|c|}
\hline \multirow{2}{*}{$\begin{array}{l}\text { Kecamatan } \\
\text { Subdistrict }\end{array}$} & \multicolumn{5}{|c|}{ Tahun / Year } \\
\hline & 2013 & 2014 & 2015 & 2016 & 2017 \\
\hline \begin{tabular}{c}
\multicolumn{1}{c}{$(1)$} \\
Teluk Betung Barat
\end{tabular} & $\frac{(3)}{3243}$ & $\frac{(4)}{3350}$ & (5) & $\begin{array}{ll}(6) \\
4536\end{array}$ & $\frac{(6)}{4520}$ \\
\hline $\begin{array}{l}\text { Teluk Betung Barat } \\
\text { Teluk Betung Timur }\end{array}$ & $\begin{array}{l}3243 \\
3718\end{array}$ & $\begin{array}{l}3350 \\
3950\end{array}$ & $\begin{array}{l}3521 \\
4099\end{array}$ & $\begin{array}{l}4536 \\
4236\end{array}$ & $\begin{array}{l}4520 \\
4759\end{array}$ \\
\hline Teluk Betung Selatan & 4340 & 4576 & 4646 & 4688 & 4844 \\
\hline Bumi Waras ${ }^{20}$ & 5610 & 5526 & 5016 & 5852 & 6150 \\
\hline Panjang & 9160 & 8588 & 8620 & 8603 & 9229 \\
\hline Tanjung Karang Timur & 4084 & 3796 & 3995 & 4401 & 4517 \\
\hline Kedamaian ${ }^{3)}$ & 6034 & 6255 & 6258 & 6325 & 6657 \\
\hline Teluk Betung Utara & 4873 & 4985 & 5147 & 5234 & 5423 \\
\hline Tanjung Karang Pusat & 6986 & 6261 & 6306 & 6437 & 6828 \\
\hline Enggal * & 3091 & 3091 & 3258 & 3245 & 3315 \\
\hline Tanjung Karang Barat & 7517 & 6714 & 7759 & 7329 & 7306 \\
\hline Kemiling & 8906 & 9333 & 9639 & 10097 & 10700 \\
\hline Langkapura ${ }^{\text {I }}$ & 4158 & 4234 & 4340 & 4366 & 4701 \\
\hline Kedaton & 5691 & 5691 & 5800 & 5125 & 5163 \\
\hline Rajabasa & 4762 & 6013 & 6053 & 6162 & 6448 \\
\hline Tanjung Senang & 5170 & 5188 & 5019 & 5023 & 5455 \\
\hline Labuhan Ratu ") & 3275 & 3319 & 3401 & 3432 & 3599 \\
\hline Sukarame & 5852 & 5915 & 5915 & 6139 & 6482 \\
\hline Sukabu & & & & & \\
\hline Way $\mathrm{Ha}$ & 538 & 7546 & 7559 & 7639 & 8626 \\
\hline Jum & 0397 & 10869 & 113029 & 115686 & 121750 \\
\hline
\end{tabular}

Gambar 2. Data Jumlah Kepala Keluarga di Bandar Lampung Tahun 2013-2017

Adapun peluang yang dimiliki oleh PT Era Global Prioritas adalah meningkatnya jumlah kepala keluarga di Kota Bandar Lampung dan meningkatnya pertumbuhan ekonomi di Kota Bandar Lampung. Pengetahuan konsumen atau citra perusahaan dimata konsumen amat baik, keadaan teknologi yang semakin berkembang menjadi peluang dari PT Era Global Prioritas untuk memanfaatkannya dan dukungan dari pemerintah terkait adanya program rumah subsidi.

\begin{tabular}{|c|c|c|c|c|c|c|c|}
\hline \multirow{2}{*}{ Komponea Pengeduran } & \multicolumn{7}{|c|}{ 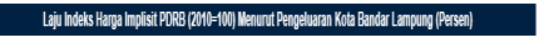 } \\
\hline & $2 \mathrm{MI1}$ & 2912 & 2913 & 2014 & 2015 & 2916 & 2017 \\
\hline $\begin{array}{l}\text { 1. Pernoluaran Konsuns Rumah } \\
\text { Tarngya }\end{array}$ & 6.13 & 535 & 42 & 378 & 5.18 & 500 & 465 \\
\hline 2 Pengellaran KonsunsiluPrT & 616 & 310 & 704 & 822] & 833 & 780 & 3.60 \\
\hline $\begin{array}{l}\text { 3. Pengeliaran Konsunsi } \\
\text { Pennentzh }\end{array}$ & 9.70 & 866 & 5.76 & 838 & 341 & 3.4 & 220 \\
\hline 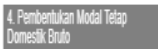 & 5.56 & 6) & 306 & 318 & 488 & 400 & 490 \\
\hline 5. Peuvataran Inertibi & 566.10 & .63 .7 & .35359 & .386 & .694 & .113 .11 & 20360 \\
\hline 6. Espourarang den Jasa & 2480 & 588 & 1000 & 037 | & 635 & 254 & 497 \\
\hline 7. Dikurangi impor Barang dan Jass & 255 & 846 & 1088 & .976 & 669 & 3.47 & 1.13 \\
\hline POPB Kota Bantar Lampung & 4.5.5 & 4000 & 418 & 6000 & 49] & 602 & 680 \\
\hline
\end{tabular}

Gambar 3. Pertumbuhan PDRB (Produk Domestik Regional Bruto) Kota Bandar Lampung Tahun 2011

$$
-2017
$$

Kelemahan dari PT Era Global Prioritas adalah kurangnya memanfaatkan kecanggihan teknologi atau internet seperti membuat website atau blog sehingga membuat kurang efektifnya memasarkan produknya. Adapun ancaman-ancaman 
perusahaan yakni kenaikan harga BBM yang berakibat meningkatnya biaya operasional, meningkatnya harga dollar, meningkatnya laju inflasi, tingginya tingkat persaingan karena banyaknya perusahaan yang bergerak di sektor properti baik perusahaan yang tergabung dengan developer BTN Properti dan yang tergabung dalam Himpunan Pengembang Pemukiman dan Perumahan Rakyat (HIMPERRA) maupun yang tidak tergabung, serta dari perusahaan baru. Tingginya tingkat persaingan dalam berbagai bisnis saat ini menuntut setiap manajemen perusahaan menemukan strategi khusus untuk menciptakan keunggulan bersaing.

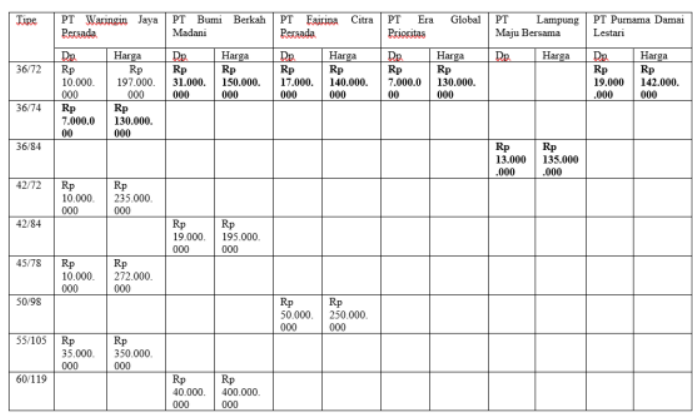

Gambar 4. Harga Properti Perusahaan yang Tergabung Dalam HIMPERRA Tahun 2018

Berdasarkan tabel diatas yang peneliti bahas adalah perumahan bersubsidi yang bertipe 36/72, 36/74 dan 36/84. Dapat dilihat harga dan uang muka atau DP dari rumah yang dibangun oleh perusahaan berbeda-beda. Hasil observasi peneliti bahwasanya uang muka dari tipe rumah PT. Era Global Prioritas lebih kecil dibanding pesaing atau perusahaan lainnya. Harga uang muka atau DP berbeda-beda karena harga jual setiap tipe rumah itu berbeda tergantung dari harga tanahnya.

Tabel 4

Jumlah Unit Rumah yang Terelisasi oleh Perusahaan yang Tergabung dalam HIMPERRA Tahun 2018

\begin{tabular}{ccc}
\hline \multirow{2}{*}{ Bulan } & $\begin{array}{c}\text { Jumlah } \\
\text { Unit }\end{array}$ & Jumlah Pendapatan \\
\hline
\end{tabular}

\begin{tabular}{lcl}
\hline & Type 36/72 & \\
\hline Januari & 6 & Rp. 738.000.000 \\
Februari & 8 & Rp. 984.000 .000 \\
Maret & 6 & Rp. 738.000.000 \\
April & 7 & Rp. 861.000.000 \\
Mei & 10 & Rp. 1.230 .000 .000 \\
Juni & 11 & Rp. 1.353.000.000 \\
Juli & 17 & Rp. 2.091.000.000 \\
\hline \multicolumn{1}{c}{ TOTAL } & $\mathbf{6 5}$ & Rp. 7.995.000.000 \\
\hline
\end{tabular}

Sumber: Laporan Penjualan PT. Era Global Prioritas, 2018

PT. Era Global Prioritas telah menetapkan target penjualan pada tahun 2018 adalah sebesar $10 \mathrm{M}$ yang berdasarkan pada jumlah total bangunan yang dibangun pada tahun 2018. Berdasarkan tabel laporan diatas, total penjualan sampai dengan bulan September berjumlah RP 7.995.000.000 yang artinya perusahaan belum mencapai target penjualannya pada tahun 2018 ini. Oleh karena itu, PT Era Global Prioritas harus terus meningkatkan strateginya dan mampu mencapainya dengan menerapkan strategi bisnis yang tepat.

Menurut David (2011), strategi merupakan sarana bersama dengan tujuan jangka panjang yang hendak dicapai (Khairo, 2019). Sedangkan menurut Kotler (2000), strategi adalah suatu rencana permainan untuk mencapai sasaran yang dinginkan dari suatu unit bisnis (Rigawa et al., 2015), dan menurut Rangkuti (2001), strategi merupakan alat untuk mencapai tujuan perusahaan dalam kaitannya dengan tujuan jangka panjang, program tindak lanjut, serta prioritas alokasi sumber daya (Pradipa Artawan et al., 2014). Perusahaan yang memiliki strategi yang baik akan mampu menghadapi persaingan, dalam hal ini maka perlu diadakan evaluasi terhadap keadaan dan kondisi riil perusahaan. Analisis yang dapat digunakan adalah analisis SWOT.

Menurut Kotler dan Armstrong (2008), Analisis SWOT adalah penilaian menyeluruh terhadap kekuatan (Strengths), kelemahan (Weaknesses), peluang 
(Opportunities), dan ancaman (Threats) suatu perusahaan (Gunawan, 2019). Analisis ini diperlukan untuk menentukan beberapa strategi yang ada di perusahaan. Analisis SWOT mencakup lingkungan internal dan eksternal perusahaan (Srinadi, 2016). Secara internal kerangka kerjanya menguraikan kekuatan dan kelemahan pada dimensi kunci misalnya kinerja keuangan dan sumber daya, sumber daya manusia, fasilitas dan kapasitas produksi, pangsa pasar, persepsi pelanggan terhadap kualitas produk, harga dan ketersediaan produk, organisasi komunikasi. Penilaian terhadap lingkungan eksternal termasuk informasi pasar, pelanggan dan persaingan, kondisi ekonomi tren sosial, teknologi dan peraturan pemerintah.

Berdasarkan pembahasan di atas, maka penelitian ini bertujuan untuk mengetahui strategi bisnis yang digunakan oleh PT. Era Global Prioritas dan merekomendasikan prioritas strategi yang dapat diterapkan oleh PT. Era Global Prioritas.

\section{TINJAUAN TEORITIS}

\section{Manajemen}

Menurut Richard L. Daft (2002), Manajemen adalah pencapaian sasaransasaran organisasi dengan cara yang efektif dan efisien melalui perencanaan pengorganisasian, kepemimpinan dan pengendalian sumber daya organisasi (Fadillah et al., 2020). Sedangkan menurut The Liang Gie (1982), Manajemen adalah unsur yang merupakan rangkaian perbuatan menggerakkan anggota organisasi dan mengarahkan segenap fasilitas kerja agar tujuan organisasi yang bersangkutan benarbenar tercapai (Alimin, 2018).

Berdasarkan pengertian di atas penulis dapat menyimpulkan bahwa manajemen adalah proses penggunaan sumber daya organisasi dengan menggerakkan anggota organisasi untuk mencapai tujuan organisasi secara efektif dan efisien. Manajemen perusahaan yang baik dan tepat akan menghasilkan output perusahaan yang efektif dan efisien dan hal ini akan mendukung tercapainya tujuan perusahaan. Efektif berarti bahwa tujuan dapat dicapai sesuai dengan perencanaan, sementara efisien berarti bahwa tugas yang ada dilaksanakan secara benar, terorganisir, dan sesuai dengan jadwal.

Proses manajemen yaitu POLC (Planning, Organizing, Leading, Controlling) (Genoveva et al., 2015). Perencanaan merupakan definisi mengenai organisasi di masa depan dan cara mencapai tujuannya. Perencanaan berarti penentuan sasaran sebagai pedoman kinerja organisasi di masa depan, ditambah dengan penetapan tugas serta alokasi sumber daya yang diperlukan untuk mencapai sasaran organisasi. Ketiadaan rencana atau perencanaan yang buruk dapat menjatuhkan kinerja organisasi. Dalam proses manajemen, rencana jangka panjang untuk kelangsungan organisasi (usaha) sangat diperlukan. Perkembangan organisasi sangat bergantung salah satunya oleh perencanaan yang baik dan tepat sasaran untuk organisasi, tanpa perencanaan, kelangsungan organisasi kedepannya tidak terjamin (Herwati et al., 2021).

Pengorganisasian biasanya mengikuti perencanaan dan mencerminkan organisasi yang mencoba untuk menyelesaikan rencana itu. Pengorganisasian melibatkan penetapan dan pengelompokan tugas ke departemen, dan alokasi berbagai sumber daya ke berbagai departemen (Rachman, 2015). Melalui pengorganisasian diharapkan organisasi bersifat lebih sistematik dan tim lebih mempunyai tanggung jawab. Hal itu berguna untuk manajemen pribadi menempati posisi yang seharusnya. 


\section{Strategi Bisnis}

Menurut Ward dan Peppard (2002), strategi bisnis adalah sekumpulan tindakan terintegrasi yang bertujuan untuk mencapai tujuan jangka Panjang dan kekuatan perusahaan untuk menhadapi para pesaing (Irfanudin et al., 2020). Suatu strategi bisnis biasanya meliputi Vision, Mission, Business Driver, Objectives, Strategies, Critical Success Factors (CSF), dan Business Area Plans.

Vision adalah pencapaian dari sebuah misi atau dapat diartikan sebagai sebuah pandangan masa depan dari sebuah bisnis yang menjadi tujuan umum sebuah perusahan. Mission adalah pernyataan yang memberikan arahan tentang apa yang akan dilakukan oleh sebuah perusahaan dalam mencapai visinya. Business Driver adalah beberapa factor kritis pendorong perubahan yang dapat memberikan fokus pada bisnis sehingga dapat memenuhi sasarannya. Objectives adalah sasaran-saran yang ditetapkan dan harus dipenuhi oleh perusahaan dalam pencapaian visi perusahaan.

Strategies adalah kebijakan atau Tindakan langsung yang dipilih perusahaan sebagai alat untuk mencapai tujuan dan memenuhi misinya. Critical Success Factors (CSF) adalah beberapa area kunci dimana sesuatu harus berjalan dengan baik shingga keberhasilan bisnis dapat dicapai. Dan yang terakhir adalah Business Area Plans, yaitu perencanaan dari berbagai area bisnis yang ada dan berkaitan dengan strategi Bisnis perusahaan (Asmarandana, 2018).

\section{Matriks EFE (External Factor Evaluation) dan IFE (Internal Factor Evaluation)}

Matriks EFE merupakan alat yang memungkinkan perencana strategi di dalam meringkas dan mengevaluasi informasi ekonomi, sosial budaya, lingkungan, politik, pemerintah, hukum, teknologi dan persaingan. Matriks ini membantu manajer dalam mengorganisir faktor-faktor strategik eksternal ke dalam kategori-kategori yang diterima secara umum mengenai peluang dan ancaman. Matriks IFE merupakan alat perumusan strategi yang meringkas dan mengevaluasi kekuatan kelemahan utama dalam area-area fungsional bisnis dan juga menjadi landasan untuk mengidentifikasi serta mengevaluasi hubungan diantara area tersebut (Naufal \& Achmadi, 2017).

\section{Matriks IE (Internal External)}

Matriks internal-eksternal merupakan matriks yang meringkas hasil evaluasi faktor eksternal dan internal yang menempatkan perusahaan pada salah satu kondisi didalam sembilan sel, dimana tiaptiap sel merupakan kondisi langkah yang harus ditempuh perusahaan. Matriks IE didasari pada dua dimensi kunci: total ratarata tertimbang IFE pada sumbu $\mathrm{x}$ dan total rata-rata tertimbang EFE pada sumbu $y$ (Hidayah et al., 2017).

\section{Matriks SWOT (Strengthsm Weaknesses, Oportunities, Threats)}

Analisis SWOT adalah identifikasi berbagai faktor secara sistematis untuk merumuskan strategi perusahaan (Agustina, 2016). Analisis ini didasarkan pada hubungan atau interaksi antara unsur internal, yaitu kekuatan dan kelemahan, terhadap unsur eksternal yaitu peluang dan ancaman (Sinambela et al., 2018). Sedangkan menurut David (2010), Matriks SWOT adalah sebuah alat pencocokan yang penting untuk membantu manajer mengembangkan empat jenis strategi, yaitu Strategi SO (kekuatan-peluang), Strategi WO (kelemahan-peluang), Strategi ST (kekuatan-ancaman), dan Strategi WT 
(kelemahan-ancaman) (Egim \& Nenengsih, 2019).

Hal yang penting dan menjadi kunci dalam pelaksanaan SWOT ini adalah mengidentifikasi dan menganalisis kekuatan, kelemahan, kesempatan dan ancaman yang dimiliki organisasi. Sehingga dengan analisis SWOT memungkinkan organisasi memformulasikan dan mengimplementasikan strategi utama sebagai tahap lanjut pelaksanaan dan tujuan organisasi.

\section{QSPM (Quantitative Planning Matrix)}

QSPM (Quantitative Strategik Planning Matrix) merupakan salah satu metode analisis dalam literature yang dirancang dalam penentuan daya tarik secara relatif dari berbagai alternative tindakan (Mujahid et al., 2018). Secara konseptual, QSPM memiliki daya tarik relatif dari berbagai strategi yang didasarkan sampai seberapa jauh faktorfaktor keberhasilan kritis eksternal dan internal kunci dimanfaatkan atau ditingkatkan. Daya tarik relatif dari masingmasing strategi dihitung dengan menentukan dampak kumulatif dari masing-masing faktor keberhasilan krisis ekternal dan internal. Sifat positif dari QSPM adalah rangkaian strategi ini dapat diperiksa secara berurutan atau bersamaan (Sitorus et al., 2019). Alat ini juga mengharuskan perencana strategi memadukan faktor-faktor internal dan eksternal yang terkait kedalam proses keputusan.

\section{METODE PENELITIAN}

Jenis metode penelitian yang dilakukan adalah metode penelitian kualitatif dengan pendekatan deskriptif. Pengumpulan data dengan teknik wawancara (interview), pengamatan (observasi), serta dokumentasi yang digunakan untuk mendukung penelitian ini. Populasi dan sampel adalah perusahaan properti rumah subsidi di Provinsi Lampung dalam hal ini adalah pemilik dari PT Era Global Prioritas yang diwakilkan oleh Direktur Perusahaan, karyawan administrasi dan konsumen.

Data yang diperoleh akan dianalisa secara deskriptif kualitatif, dimana sebagian data kualitatif yang diperoleh akan diangkakan sekedar untuk mempermudah penggabungan dua atau lebih data variabel kemudian setelah didapat hasil akhir akan dikualitatifkan kembali. Dalam penelitan ini perangkat analisis data yang akan digunakan adalah dengan menggunakan analisis IFE (Internal Factor Evaluation), EFE (External Factor Evaluation), IE (Internal External), SWOT (Strength, Weaknesses, Opportunities, Threats) dan QSPM.

\section{HASIL DAN PEMBAHASAN}

Berdasarkan data yang telah didapat, jawaban responden direkapitulasi kemudian dianalisis dengan metode deskriptif dan tahapan formulasi-formulasi yaitu matriks IFE dan EFE, matriks IE, SWOT dan pemilihan alternatif strategi prioritas dengan menggunakan metode QSPM. Berikut hasilnya:

\section{Analisis Matriks IFE (Internal Factor Evaluation)}

Sebelum melakukan analisis matriks IFE, dilakukan identifikasi terlebih dahulu mengenai kekuatan dan kelemahan perusahaan. Berikut adalah hasilnya: 


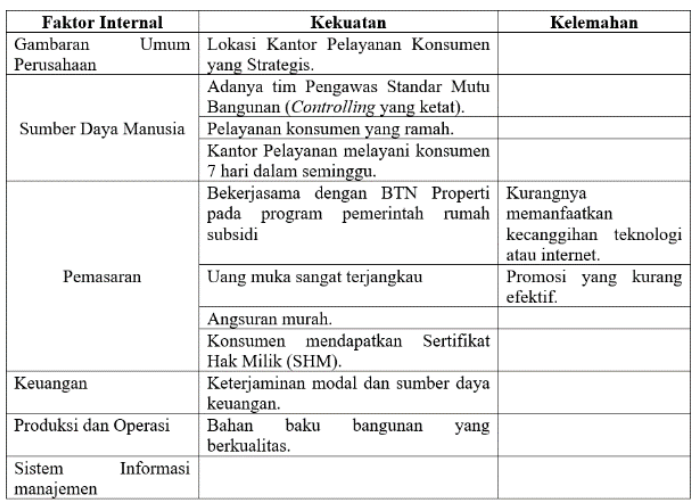

Gambar 5. Faktor-faktor Kekuatan dan Kelemahan PT. Era Global Prioritas

Setelah factor-faktor kekuatan dan kelemahan teridentifikasi, kemudian dilakukan pembobotan dan pemberian peringkat untuk mengetahui hasil akhir terhadap analisis matriks IFE. Berikut hasilnya:

\begin{tabular}{|c|c|c|c|c|c|}
\hline \begin{tabular}{|l|} 
No \\
\end{tabular} & Faktor-faktor Internal & $\Sigma$ & Bobot & Rating & Skor \\
\hline \multicolumn{6}{|c|}{\begin{tabular}{|l|} 
Kekuatan Strenghts (S) \\
\end{tabular}} \\
\hline 1 & $\begin{array}{l}\text { Lokasi Kantor Pelayanan Konsumen yang } \\
\text { Strategis. }\end{array}$ & 19 & 0.09 & 3.8 & 0.36 \\
\hline 2 & $\begin{array}{l}\text { Adanya tim Pengawas Standar Mutu } \\
\text { Bangunan (Controlling yang ketat). }\end{array}$ & 19 & 0.09 & 3.8 & 0.36 \\
\hline 3 & $\begin{array}{l}\text { Bekerjasama dengan BTN Properti pada } \\
\text { program pemerintah rumah subsidi. }\end{array}$ & 20 & 0.10 & 4 & 0.39 \\
\hline 4 & Bahan baku bangunan yang berkualitas. & 20 & 0.10 & 4 & 0.39 \\
\hline 5 & $\begin{array}{l}\text { Kantor Pelayanan melayani konsumen } 7 \\
\text { hari dalam seminggu. }\end{array}$ & 18 & 0.09 & 3.6 & 0.32 \\
\hline 6 & Uang muka sangat terjangkau. & 17 & 0.08 & 3.4 & 0.28 \\
\hline 7 & $\begin{array}{l}\text { Keterjaminan modal dan sumber daya } \\
\text { keuangan. }\end{array}$ & 19 & 0.09 & 3.8 & 0.36 \\
\hline 8 & Angsuran murah. & 18 & 0.09 & 3.6 & 0.32 \\
\hline 9 & Pelayanan konsumen yang ramah. & 19 & 0.09 & 3.8 & 0.36 \\
\hline \multirow[t]{2}{*}{10} & $\begin{array}{l}\text { Konsumen mendapatkan Sertifikat Hak } \\
\text { Milik (SHM). }\end{array}$ & 20 & 0.10 & 4 & 0.39 \\
\hline & Sub Total & 189 & 0.93 & 37.8 & 3.53 \\
\hline \multicolumn{6}{|c|}{ Kelemahan/Weaknesses } \\
\hline 1 & $\begin{array}{l}\text { Kurangnya memanfaatkan kecanggihan } \\
\text { teknologi atau internet. }\end{array}$ & 7 & 0.03 & 1.40 & 0.05 \\
\hline \multirow[t]{3}{*}{2} & Promosi yang kurang efektif. & 7 & 0.03 & 1.40 & 0.05 \\
\hline & Sub total & 14 & 0.07 & 2.80 & 0.10 \\
\hline & Total IFE & 203 & 1.00 & 40.60 & 3.62 \\
\hline
\end{tabular}

Gambar 6. Hasil Analisis Matriks IFE

Berdasarkan hasil analisis IFE di atas, diperoleh nilai kekuatan (S) sebesar $\mathbf{3 . 5 3}$ dan nilai kelemahan (W) sebesar 0.10. Hal tersebut menunjukan bahwa nilai kekuatan yang dimiliki perusahaan lebih besar dibandingkan kelemahan $(\mathrm{S}>\mathrm{W})$. (Rangkuti,2014)

\section{Analisis Matriks EFE (External Factor Evaluation)}

Sama seperti analisis matriks IFE, Sebelum melakukan analisis matriks EFE mesti dilakukan identifikasi terlebih dahulu mengenai peluang dan ancaman perusahaan. Berikut adalah hasilnya:

\begin{tabular}{|c|c|c|}
\hline Faktor Internal & Peluang & Ancaman \\
\hline Politik & $\begin{array}{l}\text { Dukungan pemerintah terkait } \\
\text { adanya program rumah subsidi }\end{array}$ & Kenaikan harga BBM \\
\hline Ekonomi & $\begin{array}{l}\text { Pertumbuhan ekonomi } \\
\text { Provinsi Lampung meningkat. }\end{array}$ & \begin{tabular}{|l} 
Laju Inflasi meningkat. \\
Meningkatnya harga \\
Rupiah terhadap Dollar \\
mempengaruhi harga \\
rumah.
\end{tabular} \\
\hline \multirow[t]{2}{*}{ Sosial } & $\begin{array}{l}\text { Pertumbuhan penduduk } \\
\text { Provinsi Lampung meningkat. }\end{array}$ & \\
\hline & $\begin{array}{llrl}\text { Pengetahuan } & \text { konsumen } \\
\text { tentang } & \text { PT } & \text { Era } & \text { Global } \\
\text { Prioritas. }\end{array}$ & \\
\hline Teknologi & $\begin{array}{ll}\begin{array}{l}\text { Teknologi } \\
\text { berkembang. }\end{array} & \text { semakin } \\
\end{array}$ & \\
\hline \multirow{2}{*}{\multicolumn{3}{|c|}{ Hukum }} \\
\hline & & \\
\hline Ancaman Pendatang Baru & & $\begin{array}{l}\text { Banyaknya perusahaan } \\
\text { property yang baru }\end{array}$ \\
\hline \multicolumn{3}{|l|}{$\begin{array}{l}\text { Daya Tawar Menawar } \\
\text { Pemasok }\end{array}$} \\
\hline \multicolumn{3}{|l|}{$\begin{array}{l}\text { Daya Tawar Menawar } \\
\text { Pembeli }\end{array}$} \\
\hline \multicolumn{3}{|l|}{$\begin{array}{l}\text { Daya Tawar Produk } \\
\text { Pengganti }\end{array}$} \\
\hline Persaingan Antar Pesaing & & $\begin{array}{l}\text { Tingginya } \\
\text { persaingan. }\end{array}$ \\
\hline
\end{tabular}

Gambar 7. Faktor-faktor Peluang dan Ancaman PT. Era Global Prioritas

Setelah factor-faktor Peluang dan Ancaman teridentifikasi, kemudian dilakukan pembobotan dan pemberian peringkat untuk mengetahui hasil akhir terhadap analisis matriks EFE. Berikut hasilnya:

\begin{tabular}{|l|l|l|l|l|l|}
\hline No & Faktor-faktor Eksternal & $\Sigma$ & Bobot & Rating & Skor \\
\hline \multicolumn{5}{|l|}{ Peluang/Opportunities } \\
\hline 1 & $\begin{array}{l}\text { Dukungan pemerintah terkait adanya } \\
\text { program rumah subsidi. }\end{array}$ & 19 & 0.15 & 3.80 & 0.55 \\
\hline 2 & $\begin{array}{l}\text { Pertumbuhan penduduk Provinsi } \\
\text { Lampung meningkat. }\end{array}$ & 19 & 0.15 & 3.80 & 0.55 \\
\hline 3 & $\begin{array}{l}\text { Pertumbuhan ekonomi Provinsi Lampung } \\
\text { meningkat. }\end{array}$ & 18 & 0.14 & 3.60 & 0.49 \\
\hline 4 & Teknologi semakin berkembang. & 20 & 0.15 & 4.00 & 0.61 \\
\hline 5 & $\begin{array}{l}\text { Dukungan pemerintah terkait adanya } \\
\text { program rumah subsidi. }\end{array}$ & 15 & 0.11 & 3.00 & 0.34 \\
\hline & Sub Total & $\mathbf{9 1}$ & $\mathbf{0 . 6 9}$ & $\mathbf{1 8 . 2 0}$ & $\mathbf{2 . 5 5}$ \\
\hline Ancaman/Threats & & & \\
\hline 1 & $\begin{array}{l}\text { Banyaknya perusahaan property yang } \\
\text { baru. }\end{array}$ & 8 & 0.06 & 1.60 & 0.10 \\
\hline 2 & Tingginya tingkat persaingan. & 9 & 0.07 & 1.80 & 0.12 \\
\hline 3 & $\begin{array}{l}\text { Meningkatnya harga Rupiah terhadap } \\
\text { Dollar mempengaruhi harga rumah. }\end{array}$ & 6 & 0.05 & 1.20 & 0.05 \\
\hline 4 & Laju Inflasi meningkat. & 8 & 0.06 & 1.60 & 0.10 \\
\hline 5 & Kenaikan harga BBM & 9 & 0.07 & 1.80 & 0.12 \\
\hline & Sub total & $\mathbf{4 0}$ & $\mathbf{0 . 3 1}$ & $\mathbf{8 . 0 0}$ & $\mathbf{0 . 5 0}$ \\
\hline & Total IFE & $\mathbf{1 3 1}$ & $\mathbf{1 . 0 0}$ & $\mathbf{2 6 . 2 0}$ & $\mathbf{3 . 0 5}$ \\
\hline
\end{tabular}

Gambar 8. Hasil Analisis Matriks EFE

Berdasarkan hasil analisis EFE di atas, maka diperoleh nilai peluang (O) 
sebesar 2.55 sedangkan nilai ancaman (T) diperoleh nilai sebesar 0.50. Hal ini menunjukkan bahwa peluang yang dimiliki perusahaan lebih besar dibandingkan ancaman (O>T). (Rangkuti, 2014)

\section{Pemilihan Aternatif Strategi}

Dari hasil perhitungan IFE didapat bahwa $S>W$ sementara pada hasil perhitungan EFE didapat $\mathrm{O}>\mathrm{T}$. Artinya posisi perusahaan memiliki kekuatan dan peluang yang lebih tinggi dibandingkan kelemahan dan ancaman. Maka pilihan alternatif strateginya adalah sebgai berikut :

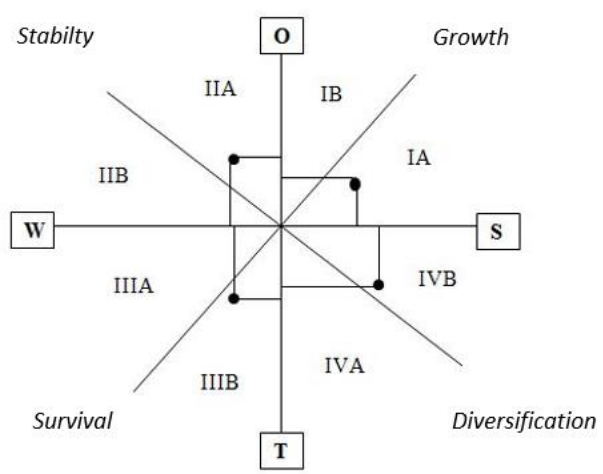

Gambar 9. Grand Strategy

Dari gambar di atas, dapat disimpulkan bahwa PT. Era Global Prioritas terletak pada kuadran IA, IIIB, IVB dan II A. Arah kebijakan PT Era Global Prioritas pada kuadran IA dengan nilai $\mathrm{S}>\mathrm{O}(3.53>2,55)$ yang menunjukkan bahwa perusahaan dalam kondisi Rapid Growth Strategy yang berarti perusahaan berada dalam posisi sedang berkembang dengan pertumbuhan yang cepat. Pada kuadran IIIB dengan nilai $\mathrm{W}<\mathrm{T}(0,10<0,50)$ menunjukkan bahwa perusahaan dalam kondisi Guerilla Strategy hal ini berarti bahwa perusahaan sedang memanfaatkan kekuatan dan peluang untuk mencari trobosan baru. Selanjutnya pada kuadran IVB dengan nilai $\mathrm{S}>\mathrm{T}$ (3.53>
0,50), hal ini menunjukkan bahwa perusahaan berada pada posisi Conglomerate Diversification Strategy yaitu perusahaan sedang melakukan persiapan diversifikasi secara luas ke berbagai kegiatan yang memberikan peluang. Kemudian yang terakhir, pada kuadran IIA dengan nilai $\mathrm{O}>\mathrm{W}(2,55>$ $0,10)$ dimana perusahaan berada pada posisi Aggresisive Maintance Strategy. Hal ini berarti perusahaan memaksimalkan menjaga stabilitas terhadap kegiatan yang berlangsung.

Dari hasil dari pemilihan strategi tersebut, didapat bahwa PT. Era Global Prioritas membangun properti dengan cara memperluas promosi, menjalin kerja sama, melakukan inovasi produk, meningkatkan manajemen mutu, dan melakukan evaluasi pemasaran dan melakukan inovasi pemasaran.

\section{Analisis Matriks IE (Internal External)}

Analisis Matriks IE merupakan matriks yang meringkas hasil evaluasi faktor eksternal dan internal yang menempatkan perusahaan pada salah satu kondisi didalam sembilan sel, dimana tiaptiap sel merupakan kondisi langkah yang harus ditempuh perusahaan. Matriks IE didasari total rata-rata tertimbang IFE pada sumbu-x dan total rata-rata tertimbang EFE pada sumbu-y. Dari hasil perhitungan pada tabel EFE dan IFE diperoleh bahwa total skor IFE $=3,62$ dan total skor EFE $=3,05$. Maka analisis matriks internal dan eksternal adalah sebagai berikut: 


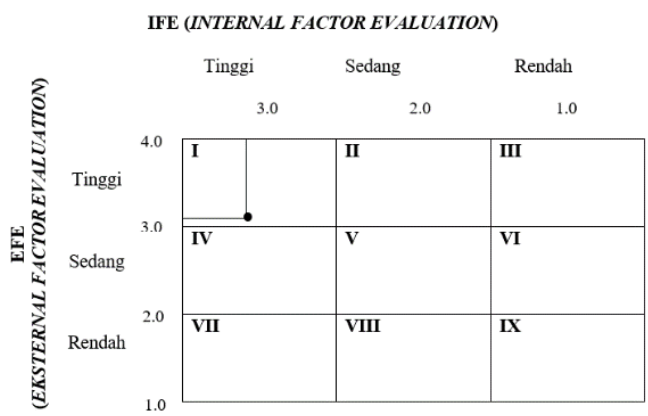

Gambar 10. Hasil Matriks IE

Dari hasil analisis di atas, diketahui bahwa PT. Era Global Prioritas berada pada posisi kuadran I. Hal ini menunjukkan bahwa PT. Era Global Prioritas berada pada posisi Growth and Build atau tumbuh dan membangun. Berdasarkan posisi tersebut alternatif strategi yang tepat digunakan oleh PT. Era Global Prioritas adalah strategi insentif (penetrasi pasar, pengembangan pasar dan pengembangan produk).

Strategi insentif yang terdiri dari strategi penetrasi pasar, yaitu mencari pangsa pasar yang lebih besar untuk produk atau jasa yang ada sekarang melalui upayaupaya pemasaran yang lebih baik. Strategi pengembangan pasar dengan cara memperkenalkan produk atau jasa saat ini ke wilayah geografis baru. Serta strategi pengembangan produk dengan cara mengupayakan peningkatan penjualan melalui perbaikan produk atau jasa saat ini dan/atau pengembangan produk atau jasa baru.

\section{Analisis Matriks SWOT (Strenghts, Weaknesses, Opportunities, Threats)}

Analisis SWOT menggunakan data yang diperoleh dari matriks IFE dan EFE. Matriks SWOT digunakan untuk menyusun strategi perusahaan. Matriks ini dapat menghasilkan empat jenis alternative strategi, yaitu Strategi SO (StrengthOpportunities), Strategi WO (WeaknessesOpportunities), Strategi ST (Strenght-
Threats), dan Strategi WT (WeaknessesThreats). Berikut hasilnya:

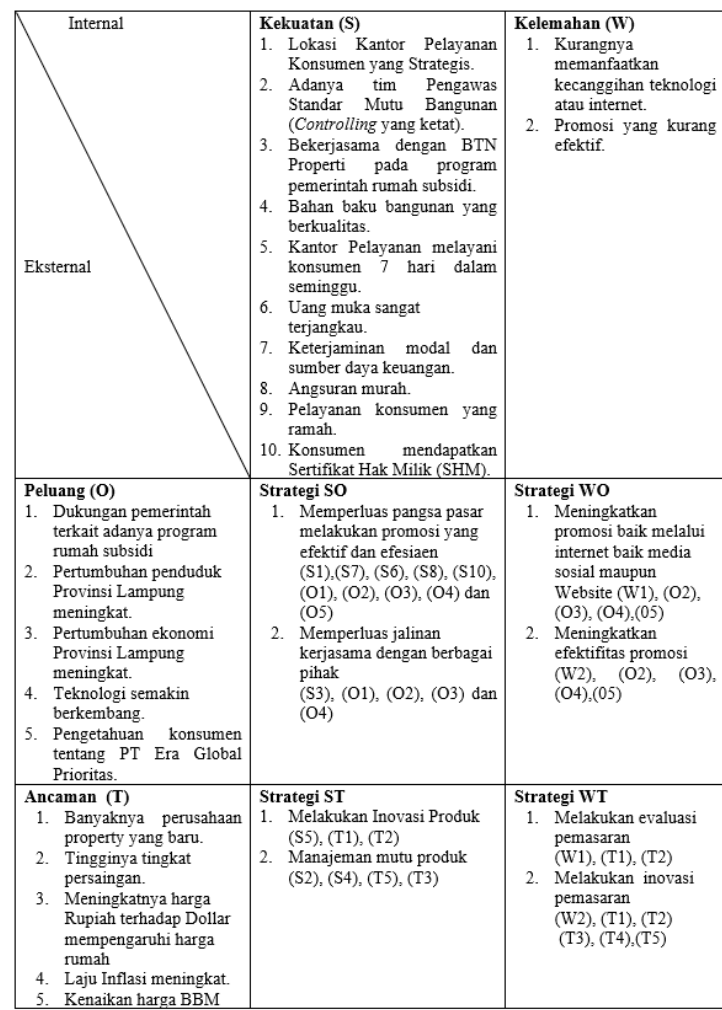

Gambar 11. Hasil Matriks SWOT

Berdasarkan analisis di atas, maka strategi yang harus dilakukan perusahaan adalah :

\section{a. Strategi Strengths and Opportunities}

1) Memperluas pangsa pasar dengan melakukan promosi yang efektif dan efisien

Strategi ini memfokuskan PT Era Global Prioritas melakukan promosi yang berkelanjutan dan membuat rencana promosi lebih luas dan menarik agar dapat menarik minat masyarakat dan meningkatkan penjualan sehingga promosi menjadi efektif dan efisien. 
Kondisi perusahaan saat ini adalah baru memiliki pangsa pasar perusahaan yang masih dalam lingkup kelas menengah ke bawah yang pembangunannya sekitar daerah Bandar Lampung, daerah Jati Agung, Lampung Selatan dan daerah Natar, Lampung Selatan.

2) Memperluas

Jalinan

Kerjasama dengan berbagai Pihak

Strategi ini bertujuan agar PT Era Global Prioritas bisa memperluas jangkauan pasar. Hal yang sudah dilakukan oleh perusahaan saat ini adalah menjalin kerjasama dengan Bank BTN dan juga asosiasi HIMPERRA (Himpunan Pengembang Pemukiman dan Perumahan Rakyat).

\section{b. Strategi Strengths and Threathness}

\section{1) Melakukan Inovasi Produk}

Strategi ini bertujuan agar produk yang diproduksi perusahaan selalu diterima dan diminati masyarakat sehingga dapat bersaing dengan para kompetitor. Hal yang sudah dilakukan oleh perusahaan saat ini adalah penggunaan atap rumah yang memakai atap baja ringan dan juga Plafon PVC.

\section{2) Manajemen Mutu Produk}

Strategi ini bertujuan agar perusahaan dapat bersaing dengan perusahaan pesaing. Strategi ini juga dilakukan agar para konsumen PT. Era Global
Prioritas dapat puas dan diharapkan dapat menjadi sarana promosi perusahaan sehingga perusahaan mampu bersaing dengan perusahaan kompetitor.

Hal yang sudah dilakukan oleh perusahaan saat ini adalah mengawasi kinerja kontraktor sehingga dapat menghasilkan produk yang bermutu dan juga melakukan promosi melalui konsumen dari teman ke teman.

\section{c. Strategi Weaknesses and Oportunities}

1) Meningkatkan Promosi baik melalui Media Sosial maupun Website

Strategi ini bertujuan untuk meningkatkan promosi melalui media social seperti WhatsApp, Facebook, Instagram, dll, juga melalui blog atau website. Hal ini agar perusahaan dapat dikenal secara luas tidak hanya di wilayah lampung namun seluruh Indonesia.

Hal yang sudah dilakukan oleh perusahaan saat ini adalah melakukan promosi melalui media sosial seperti WhatsApp, Facebook, Instagram dan dari teman ke teman.

2) Meningkatkan Efektivitas Promosi

Strategi ini bertujuan untuk memaksimalkan promosi sehingga produk dan perusahaan dikenal oleh masyarakat. Hal yang sudah dilakukan oleh perusahaan saat ini adalah melakukan iklan melalui media sosial dan penyebaran brosur. 


\section{d. Strategi Weakness and Threathness}

\section{1) Melakukan Pemasaran}

Evaluasi

Strategi ini bertujuan agar pemasaran yang akan datang dapat lebih maksimal karena adanya evaluasi. Melalui evaluasi perusahaan dapat memperbaiki kekurangan serta meningkatkan hal yang telah dianggap baik. Dalam ini, perusahaan masih jarang melakukan evaluasi pemasaran.

\section{2) Melakukan Inovasi Pemasaran}

Strategi ini bertujuan agar selalu ada pembaharuan pemasaran, sesuai dengan keadaan zaman seperti melakukan promosi melalui media sosial dan media cetak. Hal ini dapat membuat pemasaran lebih efektif dan efesien.

Dalam hal ini perusahaan belum melakukan inovasi pemasarannya, masih menggunakan metode lama yakni promosi melalui WhatsApp, Facebook, Instagram dan dari teman ke teman.

Dari ke-empat Strategi tersebut jika dirangkum akan mendapatkan hasil berikut:

Tabel 5

Alternatif Strategi yang Dianalisis Hasil Matriks SWOT

\begin{tabular}{cl}
\hline No. & \multicolumn{1}{c}{ Strategi yang dianalisis } \\
\hline 1. & $\begin{array}{l}\text { Memperluas pangsa pasar melakukan } \\
\text { promosi yang efektif dan efisien }\end{array}$ \\
2. & $\begin{array}{l}\text { Memperluas jalinan kerja sama dengan } \\
\text { berbagai pihak }\end{array}$ \\
3. & Melakukan inovasi produk \\
4. & Manajeman mutu produk
\end{tabular}

5. Meningkatkan promosi baik melalui internet baik media sosial maupun website

6. Meningkatkan efektifitas promosi

7. Melakukan evaluasi pemasaran

8. Melakukan inovasi pemasaran

\section{Analisis QSPM (Quantitative Strategic Planning Matrix)}

Secara konseptual, QSPM memiliki daya tarik relatif dari berbagai strategi yang didasarkan sampai seberapa jauh faktorfaktor keberhasilan kritis eksternal dan internal kunci dimanfaatkan atau ditingkatkan. Daya tarik relatif dari masingmasing strategi dihitung dengan menentukan dampak kumulatif dari masing-masing faktor keberhasilan krisis ekternal dan internal. Sifat positif dari QSPM adalah rangkaian strategi ini dapat diperiksa secara berurutan atau bersamaan. Alat ini juga mengharuskan perencana strategi memadukan faktor-faktor internal dan eksternal yang terkait kedalam proses keputusan. Berikut adalah hasil analisis QSPM PT. Era Global Prioritas:

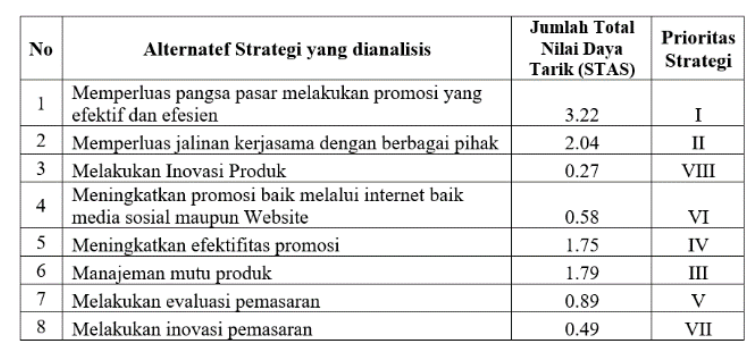

Gambar 11. Hasil Analisis QSPM

Berdasarkan hasil analisis QSPM, dapat diketahui bahwa prioritas yang harus dilakukan saat ini adalah memperluas pangsa pasar melakukan promosi yang efektif dan efisien, Strategi ini sangat penting untuk dilakukan terlebih dahulu. Lalu di ikuti dengan strategi memperluas jalinan kerja sama dengan berbagai pihak mendapatkan, manajemen mutu produk, meningkatkan efektifitas, melakukan evaluasi pemasaran, meningkatkan promosi baik melalui internet baik media sosial 
maupun website, melakukan inovasi pemasaran, dan yang terakhir melakukan inovasi produk.

\section{PENUTUP}

Dari Hasil dan Pembahasan di atas, didapat kesimpulan antara lain: 1) PT Era Global Prioritas berada pada kuadran IA S $(3.53)>\mathrm{O}(2,55)$ yaitu kekuatan perusahaan lebih besar dibandingkan peluang yang ada. Dimana arah kebijakan dalam kondisi Rapid Growth Strategy; 2) Hasil analisis IFE diperoleh nilai 3.62 dan EFE sebesar 3.05, setelah dipetakan kedalam matrik IE posisi perusahaan berada pada kuadran I yaitu tumbuh dan membangun (Growth and Build) dimana strategi yang tepat adalah strategi insentif (penetrasi pasar, pengembangan pasar dan pengembangan produk); dan 3) Hasil analisis SWOT menghasilkan 8 strategi dimana prioritas pelaksanaannya diurutkan berdasarkan QSPM, dengan alternatif: a) Memperluas pangsa pasar melakukan promosi yang efektif dan efisien; b) Memperluas jalinan kerjasama dengan berbagai pihak; c) Manajemen mutu produk; d) Meningkatkan efektifitas promosi; e) Melakukan evaluasi pemasaran; f) Meningkatkan promosi baik melalui internet baik media sosial maupun Website; g) Melakukan inovasi pemasaran; dan h) Melakukan Inovasi Produk.

Berdasarkan hasil penelitian diperoleh bahwa perusahaan berada pada kuadran I, maka saran yang diajukan adalah sesuai dengan alternatif strategi yang dihasilkan, antara lain : 1) Memperluas pangsa pasar melakukan promosi yang efektif dan efesien hal ini untuk menambah jumlah penjualan dan jumlah produksi dengan cara melakukan perluasan terhadap lingkup kelas menengah ke bawah dan juga perluasan pembangunan perumahan ke daerah luar seperti Lampung Timur, Lampung Selatan, Metro, dan daerah lainnya; 2) Memperluas jalinan kerjasama dengan berbagai pihak, jalinan kerja sama dibutuhkan untuk mempermudah proses produksi dan proses penjualan produk dengan cara menjalin kerjasama kepada pihak bank lain seperti Bank Mandiri, BRI, BCA dan juga menjalin kerjasama dengan asosiasi lainnya seperti ASPERI, APERSI, Real Estate; 3) Manajeman mutu produk perlu ditingkatkan mengingat peraturan pemerintah tentang SOP serta peningkatan jumlah kompetitor dengan cara terus melakukan pengawasan terhadap kontraktor sehingga dapat memanfaatkan sumber daya perusahaan sesuai dengan SOP perusahaan dan juga SOP pemerintah; 4) Meningkatkan efektifitas promosi, hal ini dibutuhkan untuk mempromosikan produk lebih efektif dan terencana dengan cara melakukan iklan melalui media sosial lainnya seperti memanfaatkan online shop, menyebarkan brosur ke berbagai tempat, melakukan iklan melalui media cetak dan juga melakukan pelatihan terhadap karyawan; 5) Melakukan evaluasi pemasaran terhadap kinerja pemasaran perusahaan agar dapat meningkatkan kualitas penjualan perusahaan; 6) Meningkatkan promosi baik melalui internet baik media sosial maupun Website; 7) Melakukan inovasi pemasaran untuk memberi sentuhan yang berbeda dibandingkan dengan agen properti lain; dan yang terakhir, 8) Melakukan inovasi produk dengan cara melakukan pembaharuan terhadap produk seperti menggunakan plafon yang lebih bagus lagi, memberikan bonus, mengecilkan uang muka, dan lain sebagainya.

\section{DAFTAR PUSTAKA}

Agustina, D. (2016). Penerapan Analisis 
SWOT Dan Manajemen Mutu Terpadu (TQM) Dalam Penetapan Strategi Pemasaran Toserba. Jurnal Ekonologi, 3(1), 145-149.

Alimin. (2018). Praktek Pengelolaan Dana Desa di Desa Sidorejo Kecamatan Sayung Kabupaten Demak. http://journal.stainkudus.ac.id/index.p hp/equilibrium/article/view/1268/112 7

Asmarandana, A. (2018). Perencanaan Strategis Sistem Dan Teknologi Informasi Menggunakan Framework Ward And Peppard (Studi Kasus: Perum Perhutani KPH Tasikmalaya). In Foreign Affairs. Universitas SIliwangi.

Egim, A. S., \& Nenengsih. (2019). Strategi Pengembangan Industri Makanan Khas Daerah di Kota Padang dengan Pengemasan dan Pemasaran Berbasis Teknologi. Menara Ekonomi, 5(3), 21-34.

Fadillah, D., Rahmayanti, D., \& Syifa, I. F. (2020). Studi Literatur Manajemen dan Risiko Kepatuhan pada Bank Syariah. Jurnal Akuntansi Dan Manajemen, 17(01), 38-41.

Genoveva, Amin, G., Hakim, L. N., \& Oktavia, R. (2015). Analisis FaktorFaktor yang Mempengaruhi Tingkat Kepuasan Manager, Karyawan, dan Konsumen (Studi Kasus Pada Universitas Presiden). Jurnal Manajemen, 5(1), 43-55.

Gunawan, H. (2019). Analisis SWOT Usaha Mikro Kecil dan Menengah di Industri Kreatif Cilok Neng Sari Desa Bojongsari Baru Kota Depok. PROSIDING SEMINAR NASIONAL HUMANIS 2019, 418-423.

Hamidah, H., Hartini, H., \& Mardiyati, U. (2015). Pengaruh Inflasi, Suku Bunga BI, Profitabilitas, Dan Risiko Finansial Terhadap Nilai Perusahaan Sektor Properti Tahun 2011-2013. JRMSI - Jurnal Riset Manajemen
Sains Indonesia, 6(1), 395-416. https://doi.org/10.21009/jrmsi.006.1.0 4

Herwati, I., Aditya, R. S., Munaa, M., \& Kodriyah, L. (2021). Manajemen Pelayanan Kesehatan. Literasi Nusantara.

Hidayah, N., Hufron, M., \& Slamet, A. R. (2017). Analisis Penggunaan Metode Quantitative Strategic Planning Matrix (QSPM) untuk Merumuskan Strategi Pemasaran pada Café Coklat Klasik Malang. Jurnal Ilmiah Riset Manajemen, 6(6), 55-69.

Irfanudin, A. M., Jamal, I., \& Afandi, M. F. (2020). Berbagi Bersama Kaum Dhuafa Binaan Laz Nahwa Nur yang Terdampak Covid-19. Jurnal LOKABMAS Kreatif, 1(3), 1-6.

Isnaini, A. M., \& Adnan, L. (2018). Hak Warga Negara Dalam Pemenuhan Lingkungan Tempat Tinggal yang Layak Ditinjau dari Perspektif Hukum Hak Asasi Manusia. Jurnal Jatiswara, 33(1), 1-13. https://doi.org/10.29303/jatiswara.v33 i1.158

Khairo, R. (2019). Analisis Strategi Pemasaran Pariwisata Di Desa Ketapang Raya Kecamatan Keruak, Lombok Timur. Jurnal Riset Manajemen, $\quad 19(1), \quad 8$. https://doi.org/10.29303/jrm.v19i1.34

Lakutomo, G. S. (2014). Analisis Pemasaran Terhadap Bisnis Online dalam Jaringan Sosial Internet. Universitas Muhammadiyah Surakarta.

Lesmana, B. I. (2020). Rancangan Bangun Sistem Penilaian Kinerja Pada PT.M2S. Melek IT Journal, 6(2), 7178.

Mujahid, A., Isharyani, M. E., \& Widada, D. (2018). Analisis Strategi Pemasaran Mengunakan Metode Quantitative Strategic Planning Matrik (QSPM) Studi Kasus : Borneo 
Project. Jurnal Rekayasa Sistem Industri, $\quad 7(2), \quad 111$. https://doi.org/10.26593/jrsi.v7i2.299 5.111-118

Naufal, A. F., \& Achmadi, F. (2017). Formulasi Strategi Untuk Pengembangan Pasar Industri Semen Di Jawa Timur ( Studi Kasus Perusahaan "A"). Bisma: Jurnal Bisnis Dan Manajemen, 11(2), 124138.

Pradipa Artawan, I. P., Kusuma Negara, I. M., \& Leli Kusuma Dewi, L. G. (2014). Strategi Pemasaran PT. Alliance Vast Tours Terhadap Wisatawan Pengguna Jasa Perjalanan. Jurnal IPTA， 2(2), 19-23. https://doi.org/10.24843/ipta.2014.v0 2.i02.p04

Prasastono, N., \& Pradapa, S. Y. (2012). Kualitas Produk Dan Kualitas Pelayanan Terhadap Kepuasan Konsumen Kentucky Fried Chicken Semarang Candi. Jurnal Ilmiah Dinamika Kepariwisataan, 11(2), 1323.

Primananda, I. H., Santoso, N., \& Rachmadi, A. (2020). Pengembangan Sistem Marketplace Tanah dan Property Berbasis Web dengan Pendekatan Rapid Application Development (RAD). Pengembangan Teknologi Informasi Dan Ilmu Komputer, 4(1), 200-206. http://jptiik.ub.ac.id

Rachman, F. (2015). Manajemen Organisasi Dan Pengorganisasian Dalam Perspektif Al-Qur'an Dan Hadith. Ulumuna: Jurnal Studi Keislaman, 1(2), 291-323.

Rifa'i, M., Sasongko, T., \& Indrihastuti, P. (2019). Meningkatkan Keunggulan Bersaing Produk Melalui Inovasi dan Orientasi Pasar pada Usaha Sektor Industri Kreatif di Kota Malang. Jurnal Ekbis: Analisis, Prediksi Dan Informasi, 20(1), 1194-1205.
Rigawa, A., Wirasari, I., \& Desintha, S. (2015). Perancangan Promosi Wisata Danau Linow di Sulawesi Utara. EProceding of Art \& Design, 2(1), 9396.

Septianita, Wi., Agus Winarno, W., \& Arif, A. (2014). Pengaruh Kualitas Sistem, Kualitas Informasi, Kualitas Pelayanan Rail Ticketing System (RTS) Terhadap Kepuasan Pengguna (Studi Empiris Pada PT. KERETA API INDONESIA (PERSERO) DAOP 9 JEMBER). E-Journal Ekonomi Bisnis Dan Akuntansi, 1(1), 53-56.

Sinambela, Y., Darnianti, \& Panjaitan, N. (2018). Analisis Startegi Pemasaran CV KArunia Makmur Persada (KMP) Dengan Metode SWOT. Jurnal Juitech, 2(2), 56-66.

Sitorus, B. P., Nursyamsi, I., \& Sumardi. (2019). Strategi Keunggulan Bersaing PT. Semen Tonasa Dengan SWOT Dan QSPM. Hasanuddin Journal of Bussiness Strategy, 1(1).

Srinadi, N. L. P. (2016). Analisis SWOT Sebagai Dasar Menentukan Strategi Pemasaran Kompetitif (Studi Kasus: Usaha Jasa Dekorasi X). Seminar Nasional Teknologi Informasi Dan Komunikasi 2016 (SENTIKA 2016), 9-12.

Sufriadi, D. (2018). Kualitas Pelayanan Terhadap Pelanggan Pada PT . Pos Indonesia (Persero) Banda Aceh. Jurnal Ekombis, 4(2), 121-132. http://jurnal.utu.ac.id/ekombis/article/ view/1344

Tanrifaisal, S., Matasik, Y. D. S., \& Limanto, S. (2020). Analisa Biaya Pada Proyek Rumah Tinggal Dua Lantai di Surabaya Barat. Urnal Dimensi Pratama Teknik Sipil, 9(1), 228-235. 